\title{
Assessment of experimental observables for local extinction through unsteady laminar flame calculations
}

\author{
Laurel Paxton ${ }^{\mathrm{a}}$, Andrea Giusti ${ }^{\mathrm{b}}$, Epaminondas Mastorakos ${ }^{\mathrm{b}}$, Fokion N. Egolfopoulos ${ }^{\mathrm{a}}$ \\ ${ }^{a}$ Department of Aerospace and Mechanical Engineering, University of Southern California, Los Angeles, CA 90089, \\ USA \\ ${ }^{b}$ Department of Engineering, University of Cambriddge, Trumpington Street, Cambridge, CB2 1PZ, United \\ Kingdom
}

\begin{abstract}
Unsteady premixed and non-premixed counterflow laminar flame simulations were conducted in order to investigate extinction effects on observables commonly used in turbulent combustion. $\mathrm{CH}_{4}$ and $n$ - $\mathrm{C}_{12} \mathrm{H}_{26}$ were the fuels studied, with air as the oxidizer at pressures of 1,5 , and 10 bar. It was determined that $\mathrm{CH}_{2} \mathrm{O}$ persists, compared to all other reactive species, during the extinction transient for both fuels and at all conditions, as the loss of $\mathrm{OH}$ concentration removes the dominant $\mathrm{CH}_{2} \mathrm{O}$ consumption pathway. The persistence of $\mathrm{CH}_{2} \mathrm{O}$ concentration is duplicated similarly in $\mathrm{CH}_{4}$ and $n$ - $\mathrm{C}_{12} \mathrm{H}_{26}$ premixed flames. For non-premixed flames, the results indicate that the peak $\mathrm{CH}_{2} \mathrm{O}$ concentration reduction for $n$ - $\mathrm{C}_{12} \mathrm{H}_{26}$ flames is milder compared to $\mathrm{CH}_{4}$ flames. Increasing the pressure causes an extension of reactivity, resulting in greater $\mathrm{CH}_{2} \mathrm{O}$ production and thus a delayed decay during the extinction transient. In addition, a change in the magnitude of the applied scalar dissipation rate for the non-premixed flames did not alter the trends of $\mathrm{CH}_{2} \mathrm{O}$ during extinction. Thus, caution is suggested when using $\mathrm{CH}_{2} \mathrm{O}$ in turbulent combustion experiments as a marker of the preheat zone thickness, given that increased levels of $\mathrm{CH}_{2} \mathrm{O}$ could be a result of multiple local extinction events. In addition, the product of $\mathrm{OH}$ and $\mathrm{CH}_{2} \mathrm{O}$ was found to scale well with the heat release rate for $\mathrm{CH}_{4}$ and $n-\mathrm{C}_{12} \mathrm{H}_{26}$ flames at multiple pressures. Finally, the $\mathrm{CH}^{*}$ and $\mathrm{OH}^{*}$ chemiluminescence was examined. $\mathrm{CH}^{*}$ was found to extinguish slightly before the other species and more importantly, that once its concentration is reduced to a negligible level, the flame is on its way to extinction with no chance of recovery. $\mathrm{OH}^{*}$ was determined to scale well with heat release at both 1 and 10 bar for both fuels and type of flames.
\end{abstract}

Keywords: flame extinction, $\mathrm{CH}_{2} \mathrm{O}$, chemiluminescence, counterflow flames, unsteady flames

Email address: lpaxton@usc.edu (Laurel Paxton) 


\section{Introduction}

The characterization of local extinction in turbulent combustion, a phenomenon that is not only a manifestation of finite-rate kinetic effects that have theoretical challenges but is also of practical importance for the operation of combustion devices, has been the focus of extensive research over many decades. For instance, the stability of premixed flames in afterburners has been one of the first problems studied (e.g., [1-6]). The Turbulent Non-Premixed Flame (TNF) Workshop has focused on such local extinction phenomena for years for piloted jet diffusion flames and have provided experimental databases for model validation [7-12], with special emphasis on conditional data, with the conditioning done on mixture fraction. More recently, significant activity on high Karlovitz number premixed flames [3, 13-17] is revealing local information on flame zone thickness but also on conditional statistics, with the conditioning done on progress variable. It would be helpful to supplement these one-time scalar data with information on the transient behavior of flames as they undergo extinction and how the various commonly-used scalar measurements behave through a flame extinction event.

Chemiluminescence has been used often for monitoring the presence of chemical reaction [18]. Chemiluminescence emission forms as a result of key chemical processes in the flame, where excited radicals such as $\mathrm{CH}^{*}, \mathrm{OH}^{*}$ and $\mathrm{C}_{2} *$ emit light at a characteristic wavelength as they return to a lower energy state [19]. Extensive studies have shown that under some conditions, the magnitude of the emitted light at particular wavelengths, namely $\mathrm{CH}^{*}$ and $\mathrm{OH}^{*}$, may be used as a semi-quantitative measure of the heat release rate, especially for fully premixed systems [20, 21]. Further studies at high strain rates and increased pressures also showed a strong link between $\mathrm{CH}^{*}, \mathrm{OH}^{*}$ and the heat release rate [19] though the $\mathrm{CH}^{*}$ chemiluminescence did not appear to be sensitive changes in the local strain rate [22]. In the presence of local extinction, however, which involves sharp transients in chemical species mass fractions, the way the chemiluminescence signal adapts is open to interpretation [23]. Najm et al. [24] argued that $\mathrm{CH}^{*}$ is not an adequate indicator of local extinction, as it was observed that despite a breakage of the $\mathrm{CH}^{*}$ flame surface, $\mathrm{OH}$ and $\mathrm{HCO}$ were still present in significant quantities. However, such simulations did not continue in time past the moment of $\mathrm{CH}^{*}$ breakage and did not capture the full extinction process. Recently, in a high Reynolds number experiment of hydrocarbon-air premixed flames, the absence of $\mathrm{CH}^{*}$ was correlated with local extinction [17], but it would be advantageous to know exactly when the chemiluminescence signal is lost during the extinction transient.

A similar question arises with laser diagnostic studies for flames close to extinction, where separate or simultaneous $\mathrm{OH}$ and $\mathrm{CH}_{2} \mathrm{O}-\mathrm{PLIF}$ have been used to provide statistics of local extinction [25] as well information on the behavior of the preheat layer at high turbulence levels (e.g., [26, 27]) and the local heat release rate $[16,28]$. $\mathrm{CH}_{4}$-air lean turbulent premixed flame stabilized by a bluff body close to the 
global blow-off operating condition [29] showed significant build-up of $\mathrm{CH}_{2} \mathrm{O}$ inside the recirculation zone, attributed to the presence of incomplete combustion products due to local extinctions along the flame, while in a swirl $\mathrm{CH}_{4}$ non-premixed flame, the absence of $\mathrm{OH}$ was attributed to flame lift-off from the bluff body edge [30]. As with chemiluminescence, the evolution of $\mathrm{OH}$ and $\mathrm{CH}_{2} \mathrm{O}$ during an extinction transient are important to quantify so that the interpretation of experimental observables can be made unambiguously.

This work seeks to evaluate the relevance and significance of $\mathrm{CH}_{2} \mathrm{O}$ and chemiluminescence as observables under conditions close to extinction. Questions remain regarding the role of pressure and the effect of fuel under these conditions. These questions should be addressed quantitatively in order to reliably apply the experimental methods in complex flames and reacting environments. This work proposes to fill these gaps and discuss quantitatively the behavior of experimental observables as a function of flame configuration, pressure and duration of the extinction transient for fuels relevant to practical applications. As turbulent flame studies push to higher pressures, an understanding of species behavior under extinction conditions will facilitate interpretation of diagnostic results.

Unsteady counterflow simulations provide a useful canonical configuration to study extinction relevant to the highly strained, unsteady nature of turbulence. Simulations were conducted using an unsteady premixed counterflow configuration and an unsteady non-premixed flame solved in mixture fraction space. Turbulence cannot be represented either by a sine wave or by a pulse, nevertheless exploration of these canonical problems with laminar flames can help with building insights on how reaction zones in turbulence may respond to sudden and local excursions in strain rate.

\section{Numerical methods}

\subsection{Modeling of counterflow premixed flames}

Premixed back-to-back counterflow simulations were conducted using a modified opposed jet configuration (OPPDIF) [31, 32]. The domain size was $0.5 \mathrm{~cm}$ with a mesh resolution of 2.77 microns per grid point. Unsteadiness was introduced for the reactant velocity by imposing fixed sinusoidal variation of a given amplitude around the mean exit velocity. For the cases discussed in this paper, the amplitude of the sinusoidal variations was set to produce a strain rate amplitude of approximately $10 \%$ of the starting strain rate near extinction.

Changing the frequency of the velocity variations produces three different extinction regimes [32-34]. At low frequencies, the initial increase in strain rate will cause a quasi-steady extinction. At high frequencies, flame extinction is suppressed as the flame is unresponsive to strain rate forcing (e.g., [32]). At intermediate frequencies however, flames exhibit an unsteady extinction response, characterized by a progression towards 
extinction, a recovery period and a final extinction process. All premixed flames examined in this paper are in this unsteady extinction regime and extinguish during the second period of oscillation. The frequency required for unsteady oscillation is dependent on the magnitude of the extinction strain rate $\left(K_{\text {ext }}\right)$ as well as the magnitude of the velocity fluctuation [35]; all reported strain rates $(K)$ correspond to the maximum magnitude of the axial gradient of the axial velocity profile in the hydrodynamic zone (e.g., [32]).

\subsection{Modeling of counterflow non-premixed flames in mixture fraction space}

The second configuration investigated in this work is the extinction transient of a laminar non-premixed flame. The solution is performed in mixture fraction space, with the assumption of unity Lewis number for all species. The mass fraction of every species $\alpha$, is solved by the following equation:

$$
\frac{\partial Y_{\alpha}}{\partial t}=N(\eta) \frac{\partial^{2} Y_{\alpha}}{\partial \eta^{2}}+\dot{\omega}_{\alpha}
$$

where $\eta$ denotes the mixture fraction and $N(\eta)$ is the scalar dissipation rate modeled as [36]

$$
N(\eta)=N_{0} \exp \left(-2\left[\operatorname{erf}^{-1}(2 \eta-1)\right]^{2}\right)
$$

Equations for species are coupled with an energy equation. Considering that the mixing solution leads to a linear profile of the absolute enthalpy, in the simulations performed in this work, the energy equation has simply been expressed as absolute enthalpy constant in time. The temperature is computed starting from the enthalpy and species mass fraction.

Dirichlet boundary conditions for both species and temperature are imposed at $\eta=0$ and $\eta=1$, with the former being pure air and the latter pure fuel. The temperature is assumed to be equal for fuel and oxidizer. Once the pressure, boundary conditions, and initial species composition in mixture fraction space are assigned, the only parameter affecting the solution is the scalar dissipation rate, controlled through the value of $N_{0}$. Preliminary computations have been performed to find the extinction scalar dissipation rate $N_{0, \text { ext }}$, i.e. the minimum value of $N_{0}$ for which no burning steady-state solution is possible.

The extinction transient has been simulated starting from a steady-state solution at $N_{0}=0.8 N_{0, \text { ext }}$ and imposing a step change of $N_{0}$ at $t=0$, with a value higher than $N_{0 \text {,ext }}$. In order to investigate the effect of the duration of the extinction event, for each condition three different extinction transients have been simulated by imposing an $N_{0}$ equal to $1.1 N_{0 \text {,ext }}, 1.2 N_{0, \text { ext }}$ and $1.5 N_{0, \text { ext }}$, respectively. Quantities plotted in this paper are the peak quantity values; values taken at the stoichiometric contour produced similar conclusions.

It should be noted that simulations performed in physical space produced similar phenomenon to the results observed using the mixture fraction space approach. The duplication of the observed phenomena 
Table 1: Cases investigated. The configuration is indicated by P for 'premixed' and NP for 'non-premixed'.

\begin{tabular}{ccccc}
\hline Fuel & Pressure (bar) & $T_{\mathrm{u}}(\mathrm{K})$ & Configuration & $K_{\text {ext }}\left(s^{-1}\right) / N_{0, \text { ext }}\left(s^{-1}\right)$ \\
\hline \hline \multirow{2}{*}{$\mathrm{CH}_{4}$} & 1 & 403 & $\mathrm{P}, \mathrm{NP}$ & $1830(\mathrm{P}), 249(\mathrm{NP})$ \\
& 1 & 498 & $\mathrm{NP}$ & 360 \\
& 5 & 571 & $\mathrm{P}, \mathrm{NP}$ & $9674(\mathrm{P}), 945(\mathrm{NP})$ \\
& 10 & 617 & $\mathrm{NP}$ & 1345 \\
$n-\mathrm{C}_{12} \mathrm{H}_{26}$ & 1 & 403 & $\mathrm{P}$ & 474 \\
& 1 & 489 & $\mathrm{NP}$ & 525 \\
& 5 & 571 & $\mathrm{P}, \mathrm{NP}$ & $3031(\mathrm{P}), 2028(\mathrm{NP})$ \\
& 10 & 617 & $\mathrm{NP}$ & 3353 \\
\hline \hline
\end{tabular}

using both approaches further reinforces that this phenomenon can be captured even with the assumptions made in the mixture fraction space approach. Additional information is included in supplementary material to reinforce this conclusion.

\subsection{Conditions of interest}

Both the premixed and non-premixed flame configurations were studied with $\mathrm{CH}_{4}$ and $n$ - $\mathrm{C}_{12} \mathrm{H}_{26}$ at different pressures. $\mathrm{CH}_{4}$ is commonly used in turbulent flame studies and $n-\mathrm{C}_{12} \mathrm{H}_{26}$ is representative of complex practical liquid fuels. The investigated conditions are summarized in Table 1. Configuration is indicated in the table by 'NP' for non-premixed and ' $\mathrm{P}$ ' for premixed. The flame response in the premixed case was examined for $\mathrm{CH}_{4} /$ air and $n-\mathrm{C}_{12} \mathrm{H}_{26}$ /air flames at equivalence ratio $\phi=0.7$ for 1 and 5 bar. The unburned mixture temperature $\left(T_{\mathrm{u}}\right)$ was $403 \mathrm{~K}$ at 1 bar. For higher pressures, $T_{\mathrm{u}}$ was adjusted to account for $n-\mathrm{C}_{12} \mathrm{H}_{26}$ vaporization requirements. The non-premixed flame configuration was investigated for three different pressures: 1, 5, and 10 bar. The temperature of the fuel and oxidizer was chosen to ensure the existence of pure fuel in vapor form at the respective pressure. The kinetic models used were USC-Mech II [37] for the $\mathrm{CH}_{4}$ flames and JetSurf 2.0 [38] for the $n$ - $\mathrm{C}_{12} \mathrm{H}_{26}$ flames. Both models have been extensively validated against propagation and extinction data for laminar flames and include the $\mathrm{CH}^{*} / \mathrm{OH}^{*}$ model developed by Nori and Seitzman [39]. Though the model has not been validated under extinction conditions, it has been validated against a similar range of fuels and pressures as utilized in this paper [40-42].

All quantities plotted in this paper have been scaled by the starting value of the computational cycle. 


\section{Results and discussion}

\subsection{Characterization of the extinction transient: indicators of heat release}

Extinction results will first be discussed for the 1 bar extinction case. Figure 1 illustrates the extinction process for the $\mathrm{CH}_{4}$ premixed and non-premixed flames. The results in Fig. 1 include the peak instantaneous values of species mole fractions and peak heat release rates scaled by the starting value of the computational cycle, that is $\left(\mathrm{X}_{\mathrm{i}, \max }\right)_{\text {scaled }}$ for species $\mathrm{i}$ and $\left(\dot{q}_{\mathrm{max}}\right)_{\text {scaled }}$ respectively.

Figure 1 focuses on the behavior of six key quantities, that is $\mathrm{OH}, \mathrm{HCO}$, the product of mole fractions of $\mathrm{OH}$ and $\mathrm{CH}_{2} \mathrm{O}, \mathrm{CH}^{*}$, and $\mathrm{CH}_{2} \mathrm{O}$ as well as the maximum heat release rate $\left(\dot{q}_{\max }\right)$. $X_{\mathrm{HCO}}$ and the product of $X_{\mathrm{OH}}$ and $X_{\mathrm{CH}_{2} \mathrm{O}}$ are often used as experimental markers for heat release in turbulent flames, while $\mathrm{CH}^{*}$ is produced during vigorous burning and can indicate the location of the reaction zone as it is concentrated in regions of high temperature. The results of Fig. 1a indicate that the flame experiences a period of decreased reactivity followed by recovery and then complete extinction. Extinction is indicated by the steep loss of $\dot{q}_{\max }$ and species concentrations. Figure $1 \mathrm{~b}$ shows in the non-premixed case that the application of the $N_{0}$ exceeding $N_{0 \text {,ext }}$ causes a reduction of chemical activity and eventual extinction as indicated by the loss of $\dot{q}_{\text {max }}$. $\left(X_{\mathrm{HCO} \text {,max }}\right)_{\text {scaled }}$ and $\left(X_{\mathrm{OH} \text {,max }}\right)_{\text {scaled }} \mathrm{x}\left(X_{\mathrm{CH}_{2} \mathrm{O} \text {,max }}\right)_{\text {scaled }}$ follow the temporal behavior of $\dot{q}_{\max }$ in both the premixed and non-premixed extinction transient. $\left(X_{\mathrm{CH} * \text { max }}\right)_{\text {scaled }}$ does closely follow the temporal fluctuations of the heat release.

It can be seen that Najm et al. [24] were initially correct in their hypothesis, as $\mathrm{CH}^{*}$ does disappear while there is still $\mathrm{OH}$ and $\mathrm{HCO}$ present. Yet, as $\mathrm{CH}^{*}$ disappears, $\mathrm{OH}$ and $\mathrm{HCO}$ (in addition to $\dot{q}_{\max }$ ) shortly follow. $\mathrm{CH}^{*}$ scaled well with the temporal fluctuations of $\dot{q}_{\max }$ and $\mathrm{OH}$ prior to extinction in the premixed flame, which suggests that the general extinction potential can be inferred through the $\mathrm{CH}^{*}$ behavior. In all simulations with unsteady extinction, no flame recovery was observed after the maximum $\mathrm{CH}^{*}$ concentration dropped to negligible concentrations for both premixed and non-premixed flames. Therefore, it is perhaps more accurate to treat $\mathrm{CH}^{*}$ as the first indicator that the flame is on the path to extinction and will extinguish. Though the absence of $\mathrm{CH}^{*}$ may not indicate immediate extinction, it should be treated as an indicator that extinction will occur.

\subsection{Characterization of the extinction transient: behavior of $\mathrm{CH}_{2} \mathrm{O}$ through extinction}

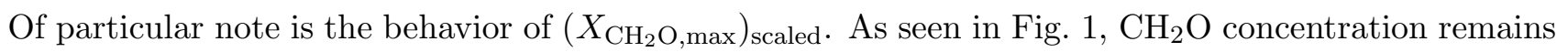
high once the extinction process initiates and subsequently decays at a more gradual rate than the other key species. This behavior is observed in both the $\mathrm{CH}_{4}$ and $n-\mathrm{C}_{12} \mathrm{H}_{26}$ non-premixed and premixed flames. In the premixed configuration, it can be noted that $\left(X_{\mathrm{CH}_{2} \mathrm{O} \text {,max }}\right)_{\text {scaled }}$ does not experience a significant response to the oscillation in strain rate, unlike $\dot{q}_{\max }$ and other species. In the non-premixed configuration, $\left(X_{\mathrm{CH}_{2} \mathrm{O}, \text { max }}\right)_{\text {scaled }}$ increases significantly during the extinction transient before decaying. 
Reaction path analysis indicates that the dominant pathway for $\mathrm{CH}_{2} \mathrm{O}$ consumption throughout the extinction transient is through the $\mathrm{CH}_{2} \mathrm{O}+\mathrm{OH} \Leftrightarrow \mathrm{HCO}+\mathrm{H}_{2} \mathrm{O}$ reaction, as can be seen in Fig. 2. Though previous studies have suggested the influence of $\mathrm{CH}_{2} \mathrm{O}$ reaction of $\mathrm{O}$ and $\mathrm{HO}_{2}$, these reactions did not feature heavily under these conditions $[43,44]$.

This dependency on $\mathrm{OH}$ suggests that a loss of $\mathrm{OH}$ concentration would results in a halt in $\mathrm{CH}_{2} \mathrm{O}$ consumption. This can be further elucidated by observing the characteristic destruction time of $\mathrm{CH}_{2} \mathrm{O}$, $\tau \equiv\left[C_{\mathrm{CH}_{2} \mathrm{O}}\right] / \dot{D}_{\mathrm{CH}_{2} \mathrm{O}}$, where $C_{\mathrm{CH}_{2} \mathrm{O}}$ and $\dot{D}_{\mathrm{CH}_{2} \mathrm{O}}$ stand for the molar concentration and molar destruction rate of $\mathrm{CH}_{2} \mathrm{O}$ respectively. $\tau$ is an indicator of $\mathrm{CH}_{2} \mathrm{O}$ consumption and the overall reaction intensity. Under vigorously burning conditions, $\tau$ remains small. When the consumption process slows and/or stops, this change can be observed through an exponential increase in $\tau$. Figure 3 provides a closer look at the behavior of $\left(X_{\mathrm{OH}, \max }\right)_{\text {scaled }},\left(\dot{q}_{\text {max }}\right)_{\text {scaled }},\left(X_{\mathrm{CH}_{2} \mathrm{O} \text {,max }}\right)_{\text {scaled }}$, and $\tau$.

Reaction cessation is indicated by the notable reduction in $\left(\dot{q}_{\text {max }}\right)_{\text {scaled }}$ and the attendant exponential increase in $\tau$. Loss of $\left(X_{\mathrm{OH}, \max }\right)_{\text {scaled }}$ occurs concurrently with this exponential increase. As expected from the reaction path analysis, this confirms that the loss of $\mathrm{OH}$ concentration correlates with the cessation of $\mathrm{CH}_{2} \mathrm{O}$ consumption. Therefore, after extinction $\mathrm{CH}_{2} \mathrm{O}$ is no longer being consumed and it is merely transported away from the previously reacting region via convection and/or diffusion. It is also worthwhile to mention that the some of the reaction processes that consume large hydrocarbon fragments to produce $\mathrm{CH}_{2} \mathrm{O}$ are also responsible for the consumption of $\mathrm{OH}$. During the extinction process therefore, $\mathrm{CH}_{2} \mathrm{O}$ consumption may also be offset by its concurrent production, responsible in part for the reduction in $\mathrm{OH}$. This relationship could also account for the relative insensitivity of $\mathrm{CH}_{2} \mathrm{O}$ to the flow oscillations of the premixed flame.

Another contributing factor to the persistence of $X_{\mathrm{CH}_{2} \mathrm{O}}$ is the insensitivity of $X_{\mathrm{CH}_{2} \mathrm{O}}$ to the temperature fluctuations present during extinction. Figure 4 illustrates the dependence on maximum temperature of the five key species and $\dot{q}_{\max }$ through the extinction transient of the premixed and non-premixed $\mathrm{CH}_{4}$ flame extinction.

The behavior of $X_{\mathrm{CH}_{2} \mathrm{O}}$ compared to the other species is particularly striking. $\left(X_{\mathrm{OH}, \max }\right)_{\text {scaled }},\left(X_{\mathrm{HCO} \text {,max }}\right)_{\text {scaled }}$, $\left(X_{\mathrm{OH} \text {,max }}\right)_{\text {scaled }} \mathrm{x}\left(X_{\mathrm{CH}_{2} \mathrm{O} \text {,max }}\right)_{\text {scaled }},\left(X_{\mathrm{CH} * \text { max }}\right)_{\text {scaled }}$ show a sharp decrease in concentration in response to small changes in temperature. This is to be expected with high activation energy processes in which small decreases in temperature will cause large reductions in reaction rates and chemical activity. $X_{\mathrm{CH}_{2} \mathrm{O}}$ however is relatively insensitive to the temperature fluctuations present. $X_{\mathrm{CH}_{2} \mathrm{O}}$ in the premixed flame exhibits only small fluctuations to the reduction of temperature during the extinction transient. This could also account for the relative insensitivity of $\mathrm{CH}_{2} \mathrm{O}$ to the flow oscillations of the premixed flame. In Fig. 4a, the initial reduction in $X_{\mathrm{CH}_{2} \mathrm{O}}$ as the flame oscillates towards extinction is due to the continuation of reaction of $\mathrm{CH}_{2} \mathrm{O}$ with $\mathrm{OH}$ balanced by against $\mathrm{CH}_{2} \mathrm{O}$ production from fuel consumption reactions. However, after 
the notable reduction of $\mathrm{OH}$ concentration at the lower temperatures, incomplete combustion continues to produce some $\mathrm{CH}_{2} \mathrm{O}$ to compete with the outwards transport of species. In the non-premixed flame shown in Fig. 4b, the buildup of $X_{\mathrm{CH}_{2} \mathrm{O}}$ is likely to be due to the presence of rich mixture fractions in the non-premixed flame. These mixture fractions continuously feed the extinction zone with $\mathrm{CH}_{2} \mathrm{O}$, which hence takes a longer time to diffuse.

The $\mathrm{CH}_{2} \mathrm{O}$ persistence after extinction therefore poses a concern in the interpretation of $\mathrm{CH}_{2} \mathrm{O}$ concentration measurement in flames with conditions near extinction or experiencing extinction events. In such cases, the presence of a $\mathrm{CH}_{2} \mathrm{O}$ signal would not coincide with the preheat layer in premixed flames, but rather exist in wider regions due to potentially multiple local extinction events at conditions of high Karlovitz numbers. It is suggested that future experimental studies use caution in interpreting the presence of $X_{\mathrm{CH}_{2} \mathrm{O}}$ as a marker of the preheat zone.

\subsection{Fuel effects with regards to $\mathrm{CH}_{2} \mathrm{O}$ extinction behavior}

Next, a closer look is taken at the $\mathrm{CH}_{2} \mathrm{O}$ behavior in $\mathrm{CH}_{4}$ and $n-\mathrm{C}_{12} \mathrm{H}_{26}$ premixed flames under extinction conditions. Both premixed flames exhibit very similar behavior. Figure 3 demonstrated that during the period of reaction and extinction, $\mathrm{CH}_{2} \mathrm{O}$ is primarily consumed through reaction with $\mathrm{OH}$ for both fuels of interest. As seen in Fig. 3 , in both $\mathrm{CH}_{4}$ and $n-\mathrm{C}_{12} \mathrm{H}_{26}$ premixed flames, $\left(X_{\mathrm{CH}_{2} \mathrm{O} \text {,max }}\right)_{\text {scaled }}$ remains significant throughout the extinction process. Once $\mathrm{OH}$ has dissipated, $\mathrm{CH}_{2} \mathrm{O}$ consumption stops.

The comparison of fuel behaviors for the non-premixed flame extinction presents a more complicated picture. Figure 5 depicts the response of the $\mathrm{CH}_{4}$ and $n-\mathrm{C}_{12} \mathrm{H}_{26}$ flame in response to the extinction transient, focusing on $\left(X_{\mathrm{CH}_{2} \mathrm{O} \text {,max }}\right)_{\text {scaled }}$ and $\left(X_{\mathrm{OH} \text {,max }}\right)_{\text {scaled }}$.

Unlike in the premixed flame however, $\left(X_{\mathrm{CH}_{2} \mathrm{O} \text {,max }}\right)_{\text {scaled }}$ for $n-\mathrm{C}_{12} \mathrm{H}_{26}$ is higher and persists longer than that for $\mathrm{CH}_{4}$. The growth behavior can be attributed to the persistence of $\mathrm{CH}_{3}$, one of the main $\mathrm{CH}_{2} \mathrm{O}$ precursors. As $n-\mathrm{C}_{12} \mathrm{H}_{26}$ has more carbon fragments to support the continued growth of $\left(X_{\mathrm{CH}_{2} \mathrm{O} \text {,max }}\right)_{\text {scaled }}$, this is partly responsible for the pronounced growth as compared to the simpler $\mathrm{CH}_{4}$ structure. There may also be contributions in the balance between $\mathrm{OH}$ consumption reactions and $\mathrm{CH}_{2} \mathrm{O}$ production.

\subsection{Effect of the duration of the extinction transient}

In the non-premixed flame simulations, three scalar dissipation rates were used to produce the extinction transient: $N_{0}=1.1 N_{0, \text { ext }}, N_{0}=1.2 N_{0, \text { ext }}, N_{0}=1.5 N_{0, \text { ext }}$. Figure 7 shows the effect of changing the applied scalar dissipation rate on $\left(X_{\mathrm{CH}_{2} \mathrm{O} \text {,max }}\right)_{\text {scaled }}$ and $\left(X_{\mathrm{OH} \text {,max }}\right)_{\text {scaled }}$.

Increasing the applied scalar dissipation rate results in a decrease of the duration of the extinction transient. However, the peak $\mathrm{CH}_{2} \mathrm{O}$ concentration and extinction behavior remain the same. As the $\mathrm{OH}$ concentration reduction occurs sooner with higher $N_{0}$, the occurrence of the $\left(Y_{\mathrm{CH}_{2} \mathrm{O} \text {,max }}\right)_{\text {scaled }}$ peak similarly 
decreases. $\mathrm{CH}_{2} \mathrm{O}$ concentrations remain high after extinction for all $N_{0}$ studied, thus the conclusions discussed in Section 3.2 are valid for changing scalar dissipation rates.

\subsection{Effect of increased pressure on experimental observables}

Pressure can notably affect burning characteristics $[45,46]$. The vast majority of applications operate at high pressures, and thus turbulent flame studies at high pressure should address the changes in flame behavior from atmospheric conditions. In particular, it is desirable to understand how changes in pressures can affect experimental observables in the event of an unsteady flame extinction.

\subsubsection{Effect of pressure on $X_{\mathrm{CH}_{2} \mathrm{O} \text {,max }}$}

To explore the potential effects of pressure on $\mathrm{CH}_{2} \mathrm{O}$ concentration in an extinction event, premixed and non-premixed flame calculations at the pressures investigated in this work are discussed next. Figure 6 shows the evolution of $\mathrm{CH}_{2} \mathrm{O}$ and $\mathrm{OH}$ concentration in a $n-\mathrm{C}_{12} \mathrm{H}_{26}$ flame with the time being scaled by the extinction strain rate; using a density-weighted strain rate instead did not change the conclusions.

The $\mathrm{CH}_{2} \mathrm{O}$ production continues during the extinction transient, as consumption rates and diffusion are not significant enough to drive down its concentration. The continued increase in $\mathrm{CH}_{2} \mathrm{O}$ concentration after $\mathrm{OH}$ loss can be attributed to extinction-induced incomplete combustion.

The value of the $\left(X_{\mathrm{CH}_{2} \mathrm{O} \text {,max }}\right)_{\text {scaled }}$ peak after extinction also increases with changing pressure. This can be attributed mostly to the extension of the reactivity with increased pressure. After the loss of $\mathrm{OH}$, $\left(X_{\mathrm{CH}_{2} \mathrm{O} \text {,max }}\right)_{\text {scaled }}$ experiences a sharp upwards growth before diffusing away. $\left(X_{\mathrm{CH}_{2} \mathrm{O} \text {,max }}\right)_{\mathrm{scaled}}$ is different for each pressure when the concentration of $\mathrm{OH}$ has been notably diminished. The extension of reactivity for the higher pressure cases allows more $\mathrm{CH}_{2} \mathrm{O}$ to be produced during the extinction transient, thus resulting in a higher peak after extinction. In addition, the increased peak value of $\left(X_{\mathrm{CH}_{2} \mathrm{O} \text {,max }}\right)_{\text {scaled }}$ takes longer to dissipate. Therefore, higher pressure causes $\left(X_{\mathrm{CH}_{2} \mathrm{O} \text {,max }}\right)_{\text {scaled }}$ to persist for longer period after extinction.

It should be noted that these conclusions are also valid for premixed flames, as illustrated in Fig. $6 \mathrm{~b}$. The extension of reactivity is clearly noted between the 1 bar and 5 bar cases, as is the increasing timeseparation between the reductions of $\mathrm{OH}$ and $\mathrm{CH}_{2} \mathrm{O}$. The increase in $\left(X_{\mathrm{CH}_{2} \mathrm{O} \text {,max }}\right)_{\text {scaled }}$ is also slightly visible as a small peak at the $t \times K_{\text {ext }}=10$ and 13 . Therefore, it can be concluded that the above observed behavior is not configuration dependent.

\subsubsection{Effect of pressure on chemiluminescence}

Chemiluminescence is widely used as an experimental observable, particularly in situations where it is too difficult or costly to apply PLIF measurements. In Section 3.1 the use of $\mathrm{CH}^{*}$ chemiluminescence in atmospheric conditions and near extinction was discussed. It was noted that under atmospheric conditions, 
though the absence of $\mathrm{CH}^{*}$ may not indicate immediate extinction, it should be treated as an indicator that extinction will occur. Exploration of the behavior of both $\mathrm{CH}^{*}$ and $\mathrm{OH}^{*}$ under pressure is also advantageous given the use of chemiluminescence in high-pressure, optically challenging environments.

As also indicated in Fig. 1, the $\mathrm{CH}^{*}$ in the non-premixed flame decays to zero at extinction, but unlike the premixed flame, it decays faster than $\dot{q}_{\max }$. When $\dot{q}_{\max }$ starts decreasing (after the initial increase due to the sudden increase of $N_{0}$ ), $\mathrm{CH}^{*}$ has already decayed to about $30 \%$ of the pre-extinction value. This is further analyzed in Fig. 8 where the time evolution of the peak value of $\mathrm{CH}^{*}$ and $\dot{q}_{\max }$ is shown for the two fuels and the two levels of pressure. The time evolution of $\mathrm{OH}^{*}$ is also included as another radical typically measured in chemiluminescence experiments. It is interesting to note that in the non-premixed flame, $\mathrm{OH}^{*}$ follows better the heat release rate profile at all the conditions, especially for $n$ - $\mathrm{C}_{12} \mathrm{H}_{26}$, whereas the $\mathrm{CH}^{*}$ evolution follows $\dot{q}_{\max }$ only for $n-\mathrm{C}_{12} \mathrm{H}_{26}$ at high pressure. Some discrepancies in the $\dot{q}_{\max }, \mathrm{OH}^{*}$ and $\mathrm{CH}^{*}$ transients arise for $\mathrm{CH}_{4}$ flames at high pressure. This shows that for non-premixed systems, chemiluminescence based on $\mathrm{OH}^{*}$, rather than $\mathrm{CH}^{*}$, might be a better marker of heat release during an extinction transient. However, the absence of both $\mathrm{CH}^{*}$ and $\mathrm{OH}^{*}$ are sufficient to indicate flame extinction potential.

\subsubsection{Correlation between the product of $X_{\mathrm{OH}}$ and $X_{\mathrm{CH}_{2} \mathrm{O}}$ and $\dot{q}_{\mathrm{max}}$}

The product of $X_{\mathrm{OH}}$ and $X_{\mathrm{CH}_{2} \mathrm{O}}$ is often used as an experimental marker for heat release in turbulent flames, as first validated by Paul and Najm [24, 47]. Studies by Nikolaou and Swaminathan [48] showed that despite the drawbacks, $X_{\mathrm{OH}} \times X_{\mathrm{CH}_{2} \mathrm{O}}$ can still be used to indicate increased chemical activity in both methane and multi-component fuels. While this diagnostic is widely implemented in turbulent flames at atmospheric pressures, its implementation under high pressure conditions is far more limited. It is desirable to know if the correlation between the product of $\mathrm{OH}$ and $\mathrm{CH}_{2} \mathrm{O}$ and $\dot{q}_{\text {max }}$ is still valid for increasing pressures. Figure 9 shows the evolution of $\mathrm{OH} x \mathrm{CH}_{2} \mathrm{O}$ concentration and $\dot{q}_{\max }$ in a $n$ - $\mathrm{C}_{12} \mathrm{H}_{26}$ premixed flame at both 1 and 5 bar.

As seen in the $\mathrm{CH}_{4}$ flames at 1 bar, $\left(X_{\mathrm{OH} \text {,max }}\right)_{\text {scaled }} \mathrm{x}\left(X_{\mathrm{CH}_{2} \mathrm{O} \text {,max }}\right)_{\text {scaled }}$ and $\dot{q}_{\text {max }}$ both exhibit similar temporal behavior. When the pressure is increased to 5 bar, this correlation remains valid, as $\left(X_{\mathrm{OH}, \max }\right)_{\text {scaled }} \mathrm{x}\left(X_{\mathrm{CH}_{2} \mathrm{O} \text {,max }}\right)_{\text {scaled }}$ tracks the extinction behavior of $\dot{q}_{\text {max }}$ quite well. The results suggest first that $\left(X_{\mathrm{OH}, \max }\right)_{\text {scaled }} \mathrm{x}\left(X_{\mathrm{CH}_{2} \mathrm{O} \text {,max }}\right)_{\text {scaled }}$ is a suitable diagnostic to approximate the behavior of $\dot{q}_{\max }$ for multiple fuels.

Furthermore, the close correlation between the product of $X_{\mathrm{OH}}$ and $X_{\mathrm{CH}_{2} \mathrm{O}}$ and $\dot{q}_{\text {max }}$ is valid at both 1 bar and 5 bar throughout the extinction process. This indicates that this experimental approach for tracking the heat release rate can likely be utilized to provide insight to flame behavior for not only a range of fuels but also high pressure, highly turbulent conditions with the potential for extinction events. 
The correlation between the heat release rate, $\dot{q}$, and the product of $X_{\mathrm{OH}}$ and $X_{\mathrm{CH}_{2} \mathrm{O}}$ is further analyzed in Figs. 10 and 11 for the non-premixed $\mathrm{CH}_{4}$ and $n-\mathrm{C}_{12} \mathrm{H}_{26}$ flames, respectively. The correlation across the entire mixture fraction space is shown at several time instants during the extinction transient. Correlation of the heat release rate with the relevant species discussed in the previous Sections, such as $X_{\mathrm{OH} *}, X_{\mathrm{CH} *}$ and $X_{\mathrm{CH}_{2} \mathrm{O}}$ are also included. Results at both $p=1$ bar and $p=10$ bar are reported.

Results show that, in the conditions investigated in this work, the heat release rate is well correlated with the $X_{\mathrm{OH}^{-}} X_{\mathrm{CH}_{2} \mathrm{O}}$ product for both $\mathrm{CH}_{4}$ and $n-\mathrm{C}_{12} \mathrm{H}_{26}$ flames. It is also interesting to note that the relation between the heat release rate and the product of $X_{\mathrm{OH}}$ and $X_{\mathrm{CH}_{2} \mathrm{O}}$ is almost linear (high value of the correlation coefficient) with the corresponding slope that does not change during the extinction. The values of $\dot{q}$ are also well correlated with $X_{\mathrm{OH}^{*}}$ and $X_{\mathrm{CH}^{*}}$ with the peak of $\dot{q}$ that corresponds with the peak of the two markers also in the transient leading to extinction. The correlation coefficient between $\dot{q}$ and such quantities is generally high, especially for $X_{\mathrm{OH}^{*}}$, however the corresponding slope of linear approximation changes during the extinction. On the contrary, as already discussed in Section $3.2, \dot{q}$ does not correlate well with $\mathrm{CH}_{2} \mathrm{O}$ which is still present also when the heat release rate is negligible. Furthermore, in general, the peak of $\dot{q}$ does not correspond to the peak of $X_{\mathrm{CH}_{2} \mathrm{O}}$.

\section{Conclusions}

In the present study, premixed and non-premixed flame calculations were performed to characterize species evolution during transient extinction. The results can be used towards improved interpretation of experimental diagnostics in turbulent combustion. $\mathrm{CH}_{4}$ and $n-\mathrm{C}_{12} \mathrm{H}_{26}$ flames were chosen for this analysis as $\mathrm{CH}_{4}$ is typical of turbulent combustion studies, and $n-\mathrm{C}_{12} \mathrm{H}_{26}$ is of interest in practical fuel studies. These fuels were studied under a variety of pressures with accompanying change in preheat temperature to ensure vaporization for $n-\mathrm{C}_{12} \mathrm{H}_{26}$.

It was observed that $\mathrm{CH}_{2} \mathrm{O}$ concentration persists after the extinction transient for both premixed and non-premixed flame configurations. Through reaction path analysis and examination of the $\mathrm{CH}_{2} \mathrm{O}$ consumption time, it was found that in both $\mathrm{CH}_{4}$ and $n-\mathrm{C}_{12} \mathrm{H}_{26}$ premixed flames, reaction with $\mathrm{OH}$ is the dominant $\mathrm{CH}_{2} \mathrm{O}$ consumption pathway. When the extinction transient passes and $\mathrm{OH}$ dissipates, $\mathrm{CH}_{2} \mathrm{O}$ consumption also ceases and is transported away. For non-premixed flames however, $n$ - $\mathrm{C}_{12} \mathrm{H}_{26}$ flames showed a greater increase in $\mathrm{CH}_{2} \mathrm{O}$ than the $\mathrm{CH}_{4}$ flame, likely due to the increased availability of hydrocarbon fragments.

Increased pressure extends the region of reactivity and causes an increase in peak $\mathrm{CH}_{2} \mathrm{O}$ concentration and longer persistence after extinction. Increased pressure also does not affect the good correlation of $\mathrm{OH}$ $\mathrm{x} \mathrm{CH}_{2} \mathrm{O}$ and $\dot{q}_{\max }$ for $n$ - $\mathrm{C}_{12} \mathrm{H}_{26}$ premixed flames. In addition, a change in the magnitude of the applied 
scalar dissipation rate for the non-premixed flames does not alter the trends of $\mathrm{CH}_{2} \mathrm{O}$ during extinction.

The behavior of $\mathrm{CH}^{*}$ and $\mathrm{OH}^{*}$ chemiluminescence was also examined during the extinction transient, and it was concluded that $\mathrm{CH}^{*}$ could serve as an indicator that flame extinction was imminent. In both the premixed and non-premixed flame configurations, it was determined that $\mathrm{CH}^{*}$ and $\mathrm{OH}^{*}$ loss precedes extinction, and no circumstances were observed when a flame remained burning shortly after a notable reduction in $\mathrm{CH}^{*} / \mathrm{OH}^{*}$ concentration. In the non-premixed flames, $\mathrm{OH}^{*}$ followed the behavior of the heat release through the transient for all pressures examined.

It should be noted that while the present studies involved a rather oversimplified set of conditions controlling the behavior of unsteady laminar flames, the results strongly suggest that unsteady effects must be taken into consideration during the interpretation of experimental data obtained in complex turbulent flame experiments in which local extinction phenomena are highly probable at large Karlovitz numbers.

\section{References}

[1] M. Russi, I. Cornet, R. Cornog, The influence of flame holder temperature on flame stabilization, Symp. (Int.) Combust. 4 (1) (1953) $743-748$.

[2] F. Wright, Bluff-body flame stabilization: blockage effects, Combust. Flame 3 (1959) 319 - 337.

[3] M. J. Dunn, A. R. Masri, R. W. Bilger, A new piloted premixed jet burner to study strong finite-rate chemistry effects, Combust. Flame 151 (1) (2007) $46-60$.

[4] S. J. Shanbhogue, S. Husain, T. Lieuwen, Lean blowoff of bluff body stabilized flames: scaling and dynamics, Prog. Energy Combust. Sci. 35 (1) (2009) $98-120$.

[5] S. Chaudhuri, S. Kostka, M. W. Renfro, B. M. Cetegen, Blowoff dynamics of bluff body stabilized turbulent premixed flames, Combust. Flame 157 (4) (2010) $790-802$.

[6] J. Kariuki, J. R. Dawson, E. Mastorakos, Measurements in turbulent premixed bluff body flames close to blow-off, Combust. Flame 159 (8) (2012) 2589 - 2607.

[7] A. Masri, R. Dibble, R. Barlow, The structure of turbulent nonpremixed flames revealed by Raman-Rayleigh-LIF measurements, Prog. Energy Combust. Sci. 22 (4) (1996) 307 - 362.

[8] R. Barlow, J. Frank, Effects of turbulence on species mass fractions in methane/air jet flames, Symp. (Int.) Combust. 27 (1) (1998) $1087-1095$.

[9] M. Ihme, H. Pitsch, Prediction of extinction and reignition in non-premixed turbulent flames using a flamelet/progress variable model: application in LES of Sandia flames D and E, Combust. Flame 155 (1) (2008) $90-107$.

[10] A. Garmory, E. Mastorakos, Capturing localized extinction in Sandia Flame F with LESCMC, Proc. Combust. Inst. 33 (1) (2011) $1673-1680$.

[11] V. N. Prasad, M. Juddoo, A. R. Masri, W. P. Jones, K. H. Luo, Investigation of extinction and re-ignition in piloted turbulent non-premixed methaneair flames using LES and high-speed OH-LIF, Combust. Theory Model. 17 (3) (2013) 483-503.

[12] International Workshop on Measurement and Computation of Turbulent Nonpremixed Flames (TNF).

[13] B. Coriton, J. H. Frank, A. G. Hsu, M. D. Smooke, A. Gomez, Effect of quenching of the oxidation layer in highly turbulent counterflow premixed flames, Proc. Combust. Inst. 33 (1) (2011) 1647 - 1654. 
[14] B. Zhou, C. Brackmann, Q. Li, Z. Wang, P. Petersson, Z. Li, M. Aldn, X. S. Bai, Distributed reactions in highly turbulent premixed methane/air flames: flame structure characterization, Combust. Flame 162 (7) (2015) 2937 $-2953$.

[15] H. Wang, E. R. Hawkes, J. H. Chen, A direct numerical simulation study of flame structure and stabilization of an experimental high Ka CH4/air premixed jet flame, Combust. Flame 180 (2017) 110 - 123.

[16] A. W. Skiba, T. M. Wabel, C. D. Carter, S. D. Hammack, J. E. Temme, J. F. Driscoll, Premixed flames subjected to extreme levels of turbulence part I: Flame structure and a new measured regime diagram, Combust. Flame 189 (2018) $407-432$.

[17] F. Carbone, J. L. Smolke, A. M. Fincham, F. N. Egolfopoulos, Comparative behavior of piloted turbulent premixed jet flames of C1C8 hydrocarbons, Combust. Flame 180 (Supplement C) (2017) 88- 101.

[18] A. G. Gaydon, H. G. Wolfhard, Flames, their structure, radiation, and temperature, Halsted Press, 1979.

[19] Y. Hardalupas, M. Orain, Local measurements of the time-dependent heat release rate and equivalence ratio using chemiluminescent emission from a flame, Combust. Flame 139 (3) (2004) 188-207.

[20] J. G. Lee, D. A. Santavicca, Experimental diagnostics for the study of combustion instabilities in lean premixed combustors, J. Prop. Power 19 (5) (2003) 735-750.

[21] C. S. Panoutsos, Y. Hardalupas, A. Taylor, Numerical evaluation of equivalence ratio measurement using OH and $\mathrm{CH}$ chemiluminescence in premixed and non-premixed methaneair flames, Combust. Flame 156 (2) (2009) $273-291$.

[22] B. Higgins, M. McQuay, F. Lacas, S. Candel, An experimental study on the effect of pressure and strain rate on CH chemiluminescence of premixed fuel-lean methane/air flames, Fuel 80 (11) (2011) 1583-1591.

[23] J. Rehm, P. Paul, Reaction rate imaging, Proc. Combust. Inst. 28 (2) (2000) 1775-1782.

[24] H. N. Najm, P. H. Paul, C. J. Mueller, P. S. Wyckoff, On the adequacy of certain experimental observables as measurements of flame burning rate, Combust. Flame 113 (3) (1998) $312-332$.

[25] R. Yuan, J. Kariuki, A. Dowlut, R. Balachandran, E. Mastorakos, Reaction zone visualization in swirling spray n-heptane flames, Proc. Combust. Inst. 35 (2) (2015) 1649 - 1656.

[26] A. Ratner, J. M. D. J. F. Driscoll, C. D. Carter, J. A. Mullin, Reaction zone structure of non-premixed turbulent flames in the intensely wrinkled regime, Proc. Combust. Inst. 22 (2000) 245-251.

[27] J. Driscoll, Turbulent premixed combustion: flamelet structure and its effect on turbulent burning velocities, Prog. Energy Combust. Sci. 34 (1) (2008) 91-134.

[28] S. Böckle, J. Kazenwadel, D. Shin, C. Schulz, J. Wolfrum, Simultaneous single-shot laser-based imaging of formaldehyde, OH, and temperature in turbulent flames, Proc. Combust. Inst. 28 (1) (2000) 279-286.

[29] J. Kariuki, A. Dowlut, R. Yuan, R. Balachandran, E. Mastorakos, Heat release imaging in turbulent premixed methane-air flames close to blow-off, Proc. Combust. Inst. 35 (2) (2015) 1443 - 1450.

[30] D. E. Cavaliere, J. Kariuki, E. Mastorakos, A comparison of the blow-off behaviour of swirl-stabilized premixed, non-premixed and spray flames, Flow, Turbul. Combust. 91 (2) (2013) 347-372.

[31] A. E. Lutz, R. J. Kee, J. F. Grcar, F. M. Rupley, OPPDIF: A Fortran program for computing opposed-flow diffusion flames, Tech. Rep. SAND96-8243, UC-1409, Sandia (1997).

[32] F. N. Egolfopoulos, C. S. Campbell, Unsteady counterflowing strained diffusion flames: diffusion-limited frequency response, J. Fluid Mech. 318 (1996) 1 - 29.

[33] F. N. Egolfopoulos, Dynamics and structure of unsteady, strained, laminar premixed flames, Symp. (Int.) Combust. 25 (1) (1994) $1365-1373$.

[34] F. N. Egolfopoulos, Geometric and radiation effects on steady and unsteady strained laminar flames, Symp. (Int.) Combust. 25 (1) (1994) $1375-1381$.

[35] C. Sung, C. Law, Structural sensitivity, response, and extinction of diffusion and premixed flames in oscillating counterflow, Combust. Flame 123 (3) (2000) 375 - 388. 
[36] E. E. O'Brien, T. Jiang, The conditional dissipation rate of an initially binary scalar in homogeneous turbulence, Phys. Fluids 3 (12) (1991) 3121-3123.

[37] H. Wang, X. You, A. Joshi, A. L. S. Davis, F. N. Egolfopoulos, C. K. Law, USC Mech II.

[38] H. Wang, E. Dames, B. Sirjean, D. A. Sheen, R. Tango, A. Violi, J. Y. W. Lai, F. N. Egolfopoulos, a. R. K. H. D. F. Davidson, C. T. Bowman, C. K. Law, W. Tsang, N. P. Cernansky, D. L. Miller, R. P. Lindstedt, A high-temperature chemical kinetic model of $n$-alkane (up to $n$-dodecane), cyclohexane, and methyl-, ethyl-, $n$-propyl and $n$-butyl-cyclohexane oxidation at high temperatures.

[39] V. Nori, J. Seitzman, Evaluation of chemiluminescence as a combustion diagnostic under varying operating conditions, 46th AIAA Aerospace Sciences Meeting and Exhibit.

[40] V. Nori, J. Seitzman, $\mathrm{CH}^{*}$ chemiluminescence modeling for combustion diagnostics, Proc. Combust. Inst. 32 (1) (2009) 895-903.

[41] E. Petersen, M. Knopp, N. Donato, F. Güthe, Assessment of current chemiluminescence kinetic models at engine conditions, ASME. J. Eng. Gas Turbines Power 134 (5).

[42] A. Hossain, Y. Nakamura, A numerical study on the ability to predict the heat release rate using $\mathrm{CH}^{*}$ chemiluminescence in non-sooting counterflow diffusion flames, Combust. Flame 161 (1) (2014) 162 - 172.

[43] S. Hochgreb, F. Dryer, A comprehensive study on CH2O oxidation kinetics, Combust. Flame 91 (3) (1992) $257-284$

[44] V. Dias, C. Duynslaegher, F. Contino, J. Vandooren, H. Jeanmart, Experimental and modeling study of formaldehyde combustion in flames, Combust. Flame 159 (5) (2012) 1814-1820.

[45] C. K. Law, Propagation, structure, and limit phenomena of laminar flames at elevated pressures, Combust. Sci. Technol. 178 (1-3) (2006) 335-360.

[46] H. K. Chelliah, C. K. Law, T. Ueda, M. D. Smooke, F. A. Williams, An experimental and theoretical investigation of the dilution, pressure and flow-field effects on the extinction condition of methane-air-nitrogen diffusion flames, Symp. (Int.) Combust. 23 (1) (1991) 503-511.

[47] P. Paul, H. Najm, Planar laser-induced fluorescence imaging of flame heat release rate, Symp. (Int.) Combust. 27 (1) (1998) 43-50.

[48] Z. Nikolaou, N. Swaminathan, Heat release rate markers for premixed combustion, Combust. Flame 161 (12) (2014) 3073-3084. 


\section{List of Figures}

1 Extinction transient for $\mathrm{CH}_{4}$ flames $\left(\mathrm{p}=1\right.$ bar, $\left.\mathrm{T}_{\mathrm{u}}=403 \mathrm{~K}\right)$. . . . . . . . . . . . . . . . 16

2 Reaction path analysis for premixed $\mathrm{CH}_{4}$ and $n-\mathrm{C}_{12} \mathrm{H}_{26}$ flames at $\mathrm{p}=1$ bar. . . . . . . . . . . . 16

3 Zoomed snapshot of evolution of $\left(X_{\mathrm{OH}, \max }\right)_{\text {scaled }},\left(X_{\mathrm{CH}_{2} \mathrm{O} \text {,max }}\right)_{\text {scaled }}$ and $\left(\dot{q}_{\text {max }}\right)_{\text {scaled }}$ with $\mathrm{CH}_{2} \mathrm{O}$ destruction timescale $\tau$ for premixed $\mathrm{CH}_{4}$ and $n-\mathrm{C}_{12} \mathrm{H}_{26}$ flames at $\mathrm{p}=1$ bar. . . . . . . . . . . . . . 16

4 Dependence of key transient species on maximum temperature, $\mathrm{p}=1$ bar, $T_{\mathrm{u}}=403 \mathrm{~K}$. . . . . . . . . 17

5 Evolution of $\left(X_{\left.\mathrm{CH}_{2} \mathrm{O}, \max \right)_{\text {scaled }}}\right.$ and $\left(X_{\mathrm{OH}, \max )_{\text {scaled }}}\right.$ for the non-premixed $\mathrm{CH}_{4}$ and $n$ - $\mathrm{C}_{12} \mathrm{H}_{26}$ flame, $N_{0}=1.1 N_{0, \text { ext }}, \mathrm{p}=1$ bar, $T_{\mathrm{u}}=498 \mathrm{~K}$. . . . . . . . . . . . . . . . . . . . . . . . . . 17

6 Evolution of $\left(X_{\left.\mathrm{CH}_{2} \mathrm{O} \text {,max }\right)_{\text {scaled }}}\right.$ and $\left(X_{\mathrm{OH}, \max )_{\text {scaled }}}\right.$ for $n-\mathrm{C}_{12} \mathrm{H}_{26}$ flame at $\mathrm{p}=1,5$, and 10 bar . . . . . 17

7 Evolution of $\left(X_{\mathrm{CH}_{2} \mathrm{O} \text {,max }}\right)_{\text {scaled }}$ and $\left(X_{\mathrm{OH} \text {,max }}\right)_{\text {scaled }}$ in $\mathrm{CH}_{4}$ non-premixed flame for three $N_{0}, \mathrm{p}=1 \mathrm{bar}$,

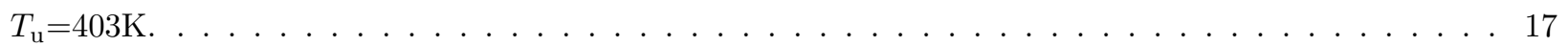

8 Evolution of scaled peak value of $\dot{q}_{\max },\left(X_{\mathrm{CH} * \text {,max }}\right)_{\text {scaled }}$ and $\left(X_{\mathrm{OH} *, \max }\right)_{\mathrm{scaled}}$ for $\mathrm{CH}_{4}$ and $n-\mathrm{C}_{12} \mathrm{H}_{26}$ at $\mathrm{p}=1$ bar and $\mathrm{p}=10$ bar $\left(N_{0}=1.1 N_{0, e x t}\right) \ldots \ldots \ldots \ldots$

9 Evolution of $\mathrm{OH} \times \mathrm{CH}_{2} \mathrm{O}$ concentration and $\dot{q}_{\max }$ for premixed $n-\mathrm{C}_{12} \mathrm{H}_{26}$ flame at $\mathrm{p}=1$ and 5 bar . . . 18

10 Correlation between heat release rate and selected quantities for non-premixed $\mathrm{CH}_{4}$ flame at $p=1$ bar (top row) and $p=10$ bar (bottom row) for the case $N_{0}=1.1 N_{0, \text { ext }}$ during the extinction transient. . . 18

11 Correlation between heat release rate and selected quantities for non-premixed $n$ - $\mathrm{C}_{12} \mathrm{H}_{26}$ flame at $p=1$ atm (top row) and $p=10$ bar (bottom row) for the case $N_{0}=1.1 N_{0, \text { ext }}$ during the extinction

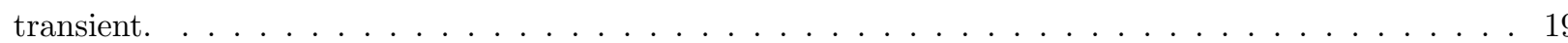




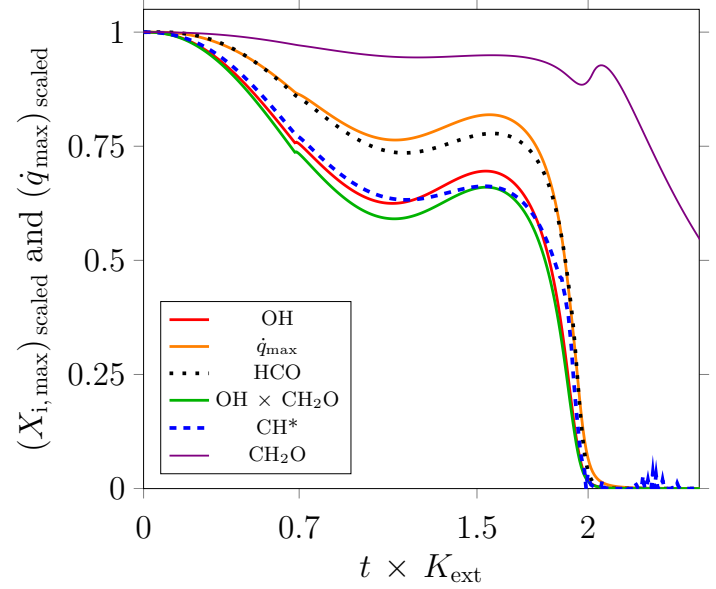

(a) Premixed $\mathrm{CH}_{4}$ flame extinction

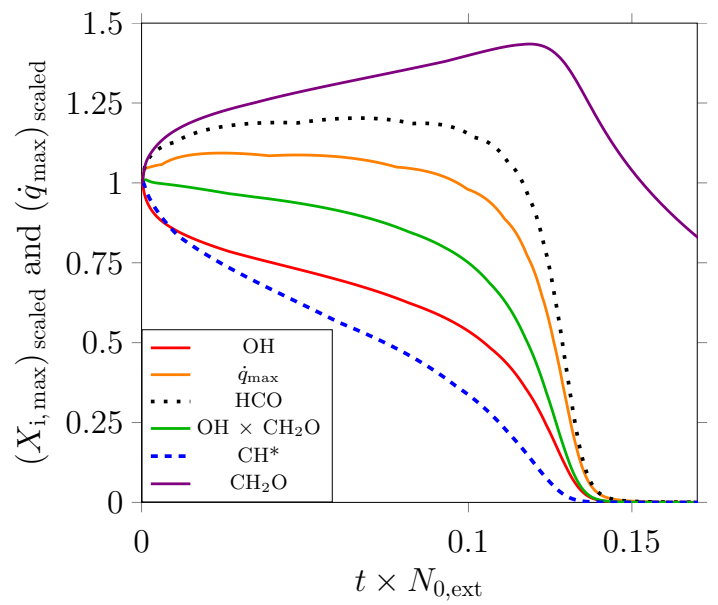

(b) Non-premixed $\mathrm{CH}_{4}$ flame extinction, $N_{0}=1.1 N_{0, \text { ext }}$

Figure 1: Extinction transient for $\mathrm{CH}_{4}$ flames $(\mathrm{p}=1$ bar, $\left.T_{u}=403 K\right)$.

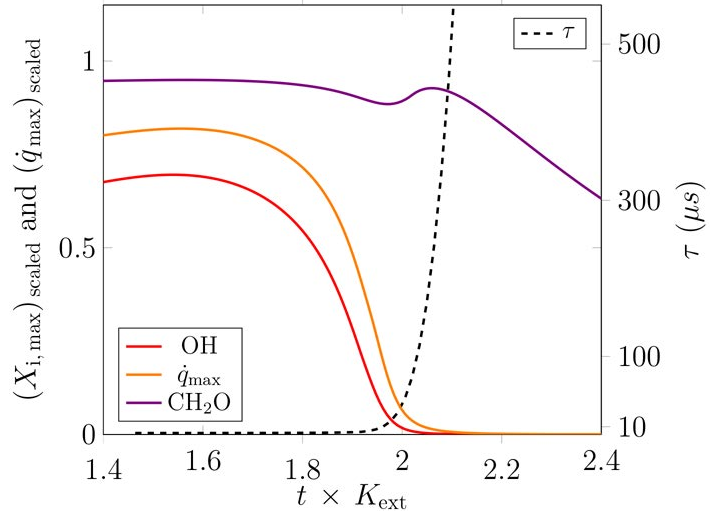

(a) $\mathrm{CH}_{4}$ flame

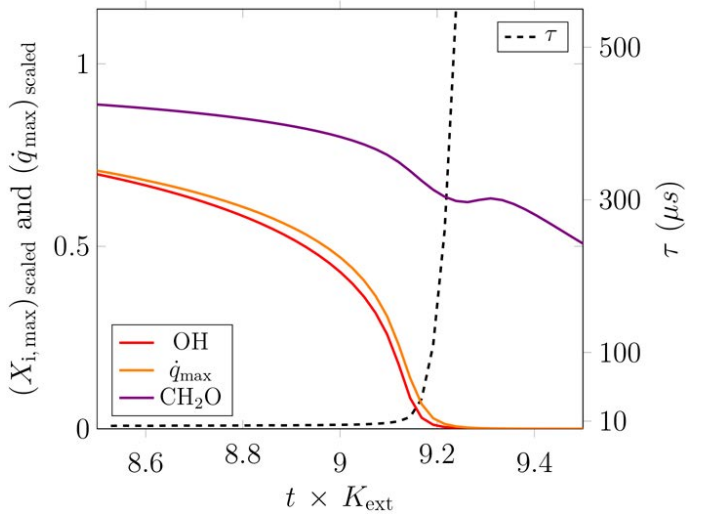

(b) $n-\mathrm{C}_{12} \mathrm{H}_{26}$ flame

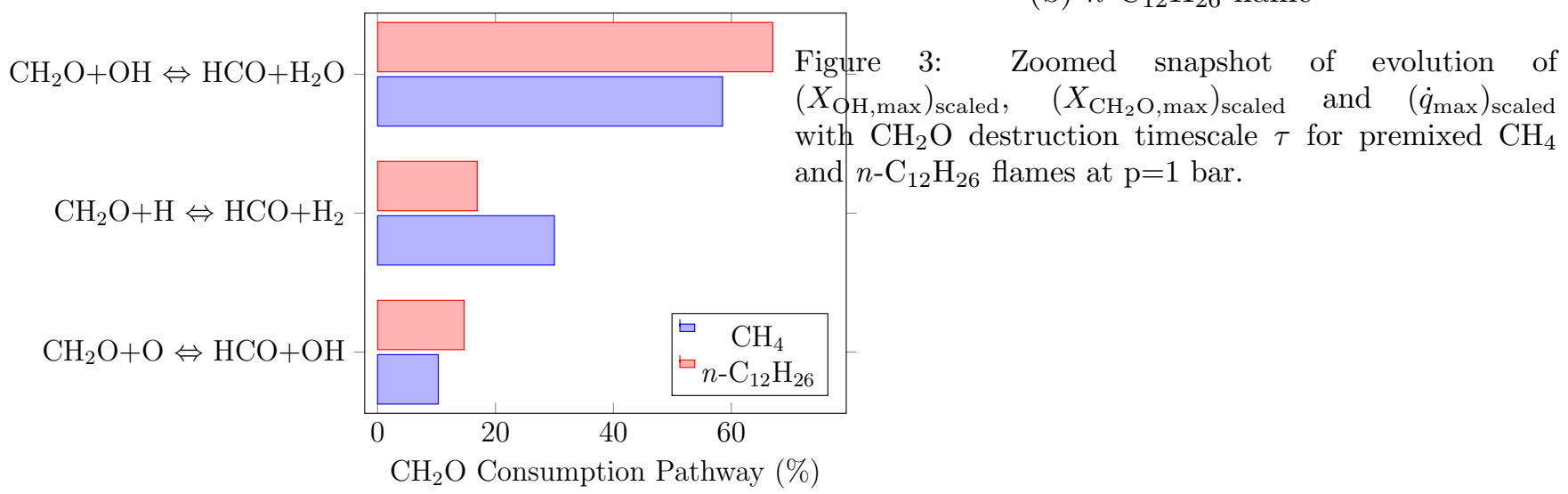

Figure 2: Reaction path analysis for premixed $\mathrm{CH}_{4}$ and $n$ - $\mathrm{C}_{12} \mathrm{H}_{26}$ flames at $\mathrm{p}=1$ bar. 


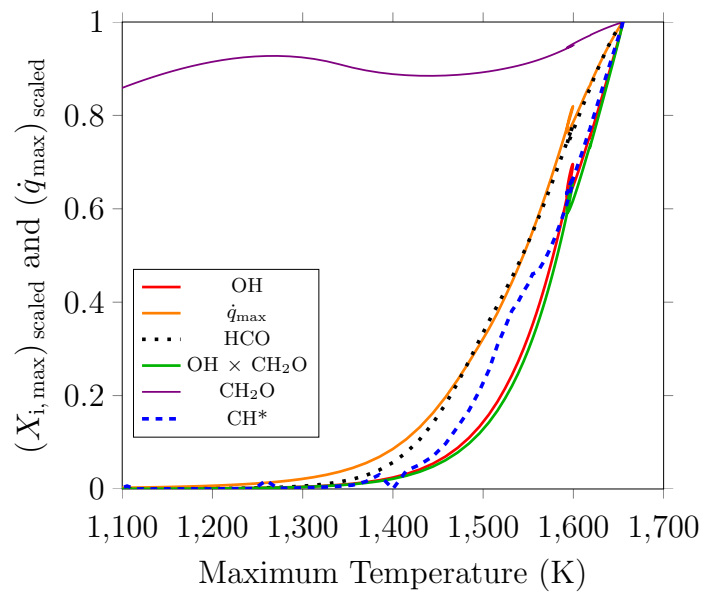

(a) Premixed $\mathrm{CH}_{4}$ flame extinction

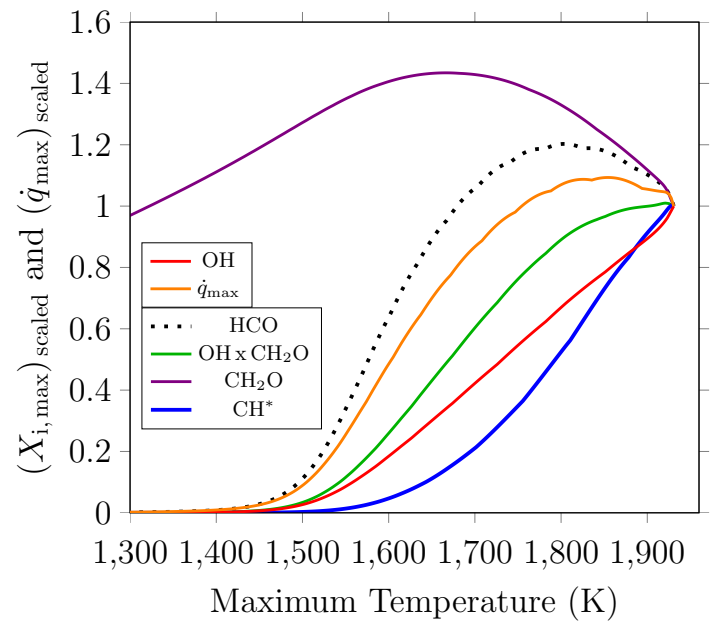

(b) Non-premixed $\mathrm{CH}_{4}$ flame extinction, $N_{0}=1.1 N_{0, \text { ext }}$

Figure 4: Dependence of key transient species on maximum temperature, $\mathrm{p}=1$ bar, $T_{\mathrm{u}}=403 \mathrm{~K}$.

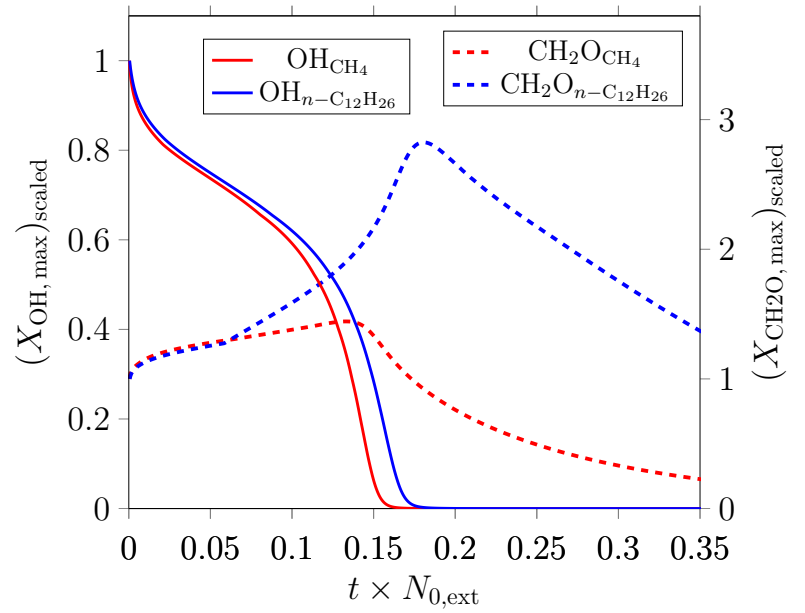

Figure 5: Evolution of $\left(X_{\left.\mathrm{CH}_{2} \mathrm{O} \text {,max }\right)_{\text {scaled }}}\right.$ and $\left(X_{\mathrm{OH}, \mathrm{max}}\right)_{\text {scaled }}$ for the non-premixed $\mathrm{CH}_{4}$ and $n-\mathrm{C}_{12} \mathrm{H}_{26}$ flame, $N_{0}=1.1 N_{0, \mathrm{ext}}, \mathrm{p}=1 \mathrm{bar}, T_{\mathrm{u}}=498 \mathrm{~K}$.

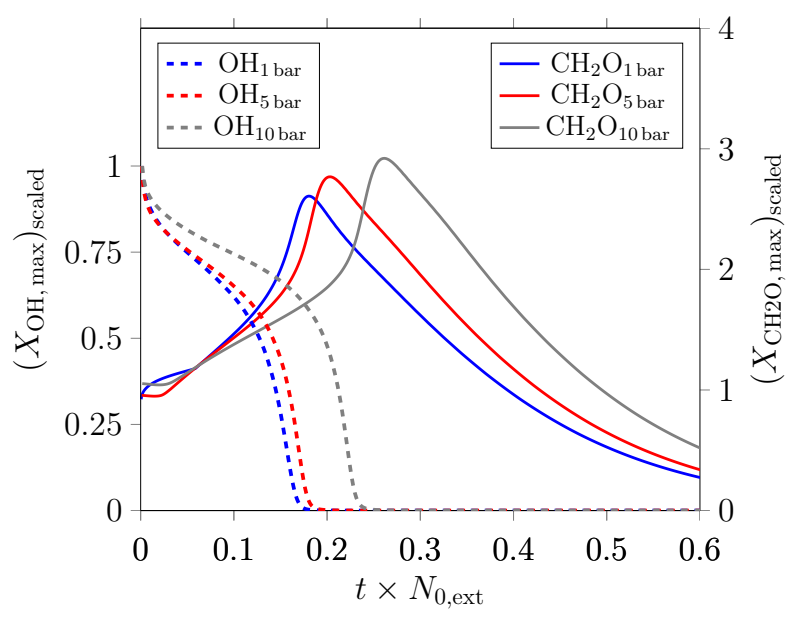

(a) Non-premixed flame $\left(N_{0}=1.1 N_{0, \text { ext }}\right)$

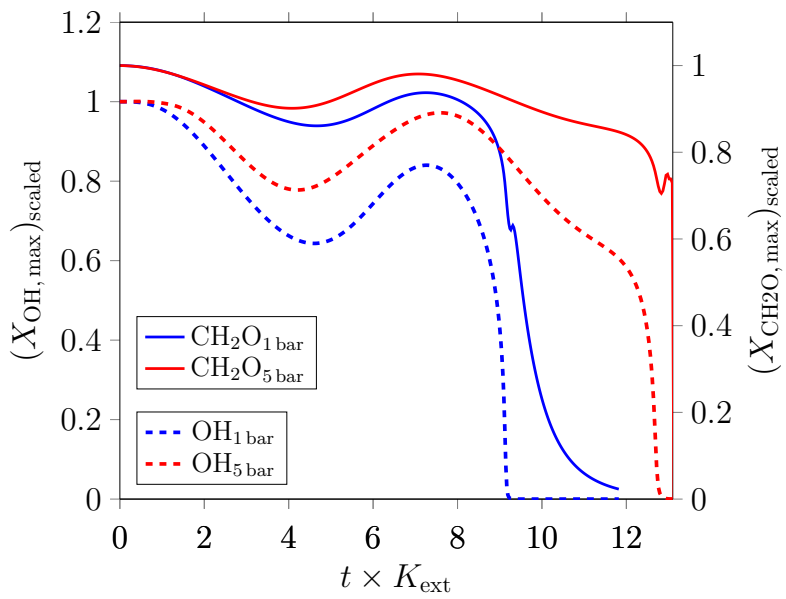

(b) Premixed flame

Figure 6: Evolution of $\left(X_{\left.\mathrm{CH}_{2} \mathrm{O} \text {,max }\right)_{\text {scaled }} \text { and }}\right.$ $\left(X_{\mathrm{OH}, \max )_{\text {scaled }}}\right.$ for $n$ - $\mathrm{C}_{12} \mathrm{H}_{26}$ flame at $\mathrm{p}=1,5$, and 10 bar

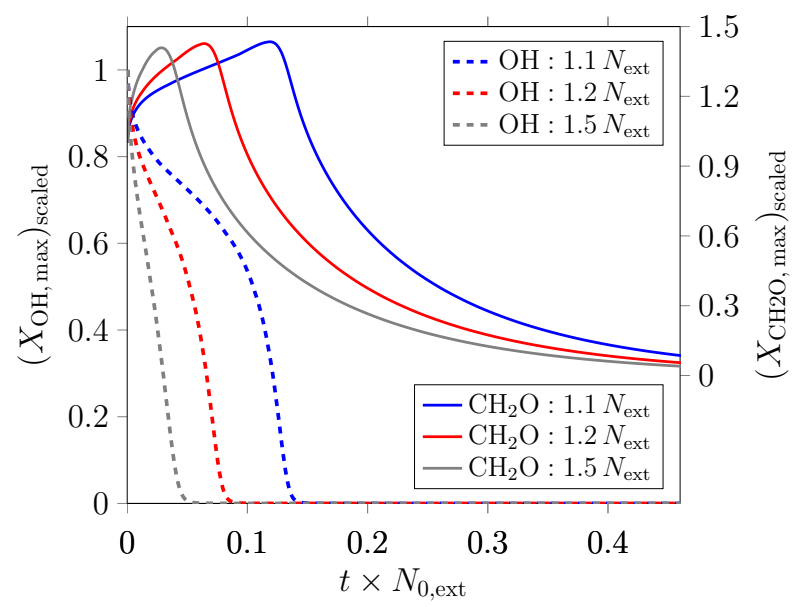

Figure 7: Evolution of $\left(X_{\mathrm{CH}_{2} \mathrm{O} \text {,max }}\right)_{\text {scaled }}$ and $\left(X_{\mathrm{OH} \text { max }}\right)_{\text {scaled }}$ in $\mathrm{CH}_{4}$ non-premixed flame for three $N_{0}, \mathrm{p}=1$ bar, $T_{\mathrm{u}}=403 \mathrm{~K}$. 


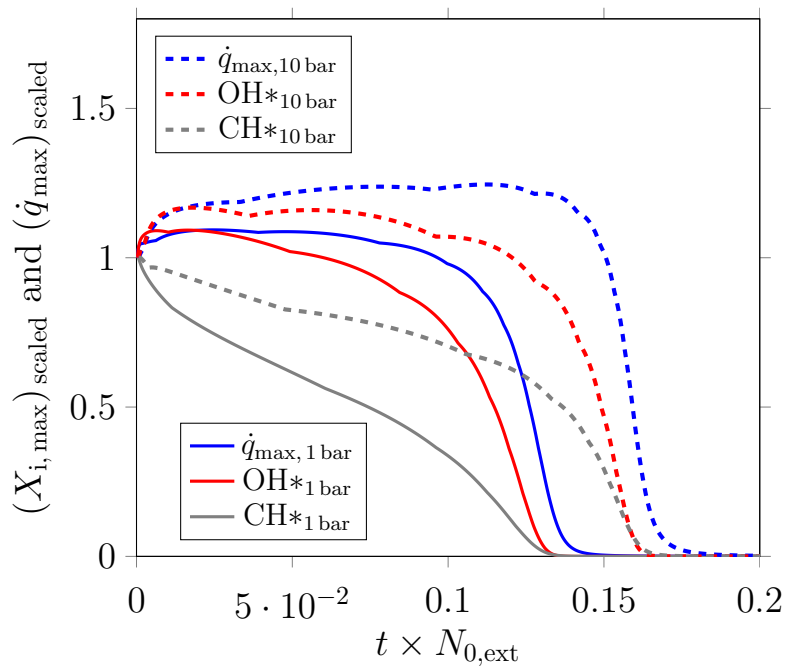

(a) $\mathrm{CH}_{4}\left(N_{0}=1.1 N_{0, \text { ext }}\right)$

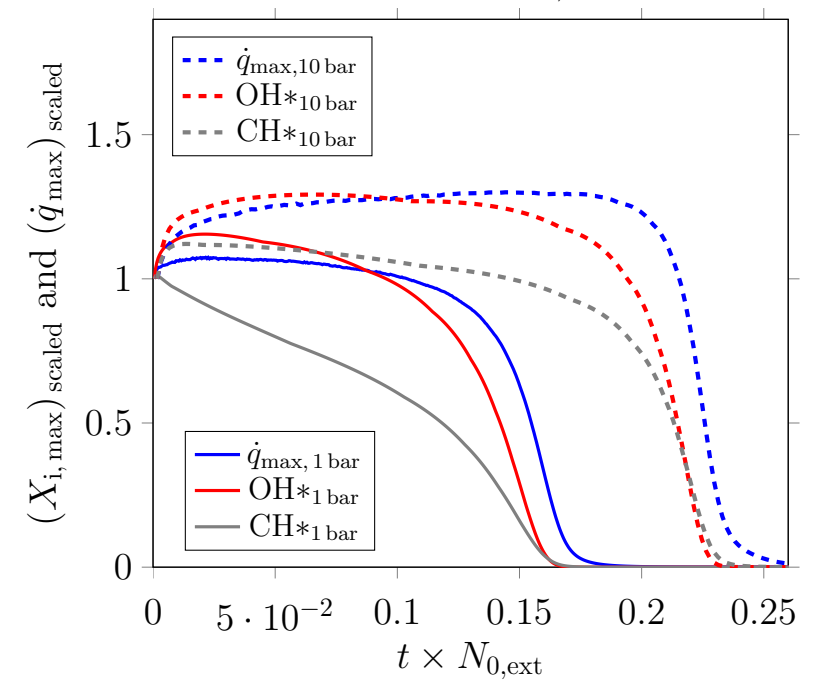

(b) $n-\mathrm{C}_{12} \mathrm{H}_{26}\left(N_{0}=1.1 N_{0, \text { ext }}\right)$

Figure 8: Evolution of scaled peak value of $\dot{q}_{\max }$, $\left(X_{\mathrm{CH} * \text { max }}\right)_{\text {scaled }}$ and $\left(X_{\mathrm{OH} * \text { max }}\right)_{\text {scaled }}$ for $\mathrm{CH}_{4}$ and $n$ $\mathrm{C}_{12} \mathrm{H}_{26}$ at $\mathrm{p}=1$ bar and $\mathrm{p}=10$ bar $\left(N_{0}=1.1 N_{0, e x t}\right)$.

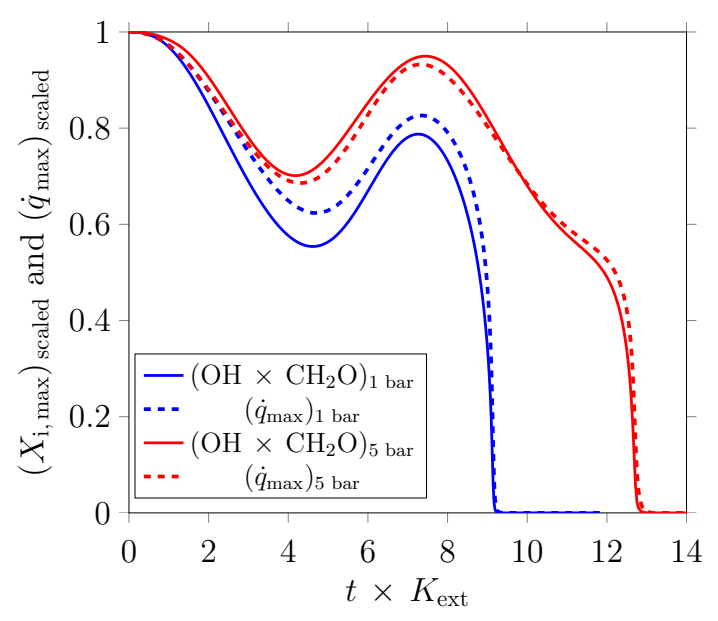

Figure 9: Evolution of $\mathrm{OH} \times \mathrm{CH}_{2} \mathrm{O}$ concentration and $\dot{q}_{\text {max }}$ for premixed $n-\mathrm{C}_{12} \mathrm{H}_{26}$ flame at $\mathrm{p}=1$ and 5 bar
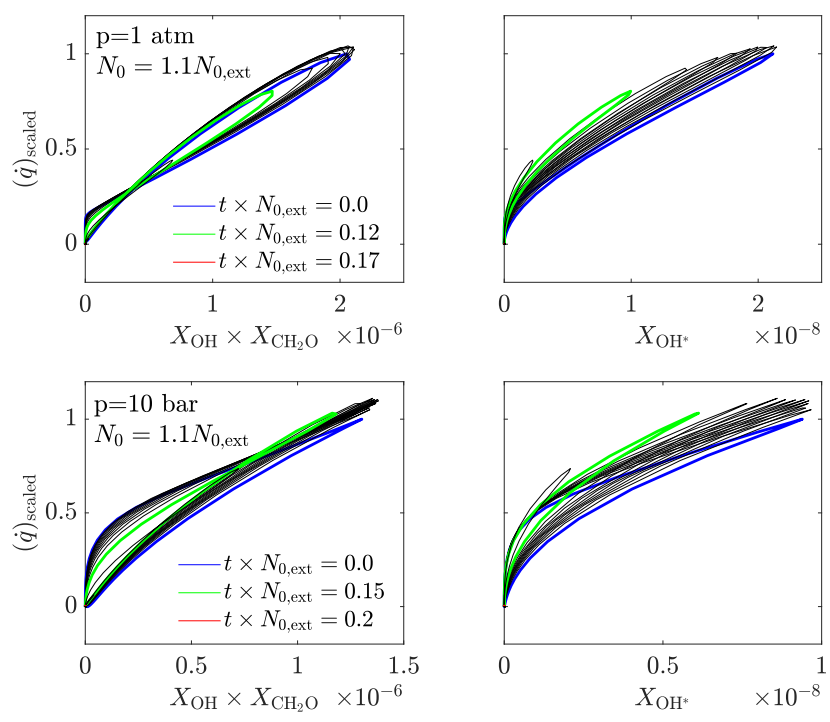

Figure 10: Correlation between heat release rate and selected quantities for non-premixed $\mathrm{CH}_{4}$ flame at $p=1$ bar (top row) and $p=10$ bar (bottom row) for the case $N_{0}=1.1 N_{0, \text { ext }}$ during the extinction transient. 

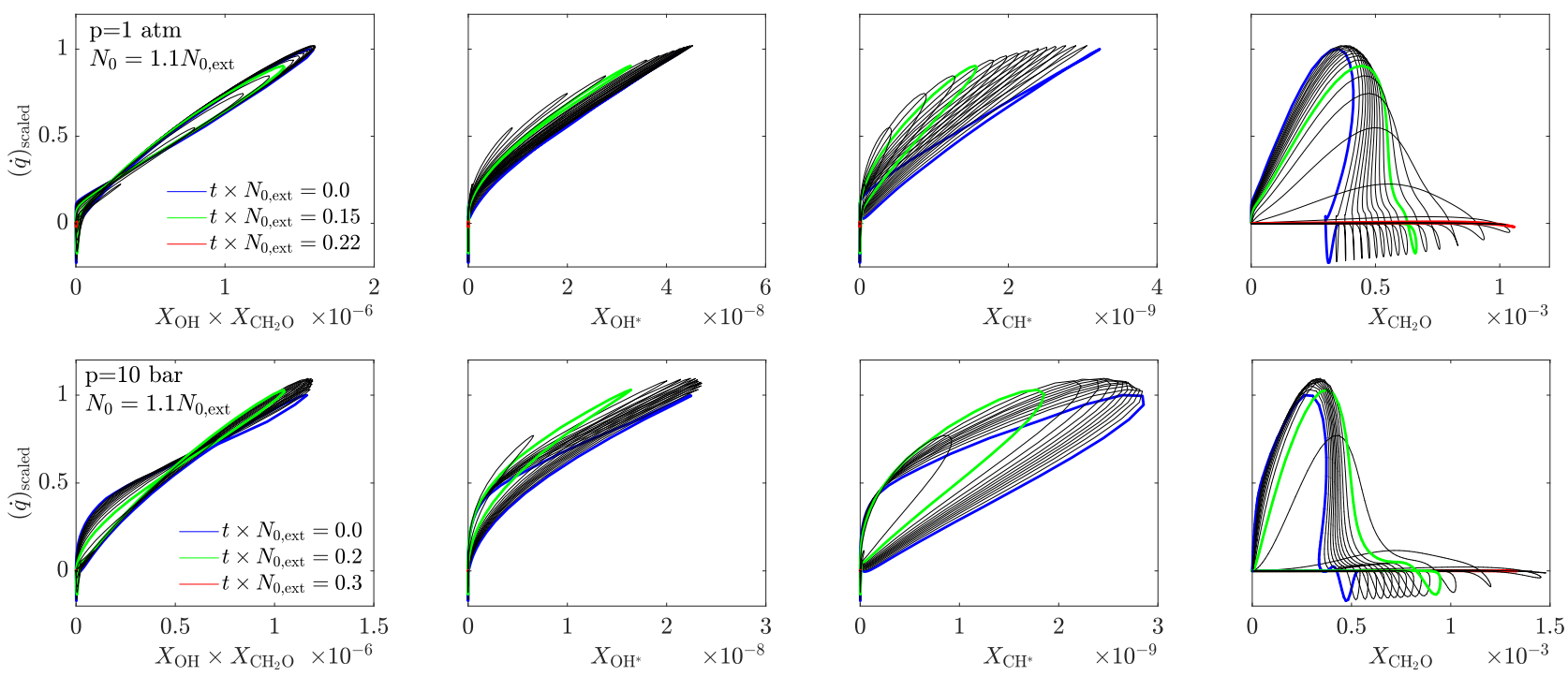

Figure 11: Correlation between heat release rate and selected quantities for non-premixed $n-\mathrm{C}_{12} \mathrm{H}_{26}$ flame at $p=1 \mathrm{~atm}$ (top row) and $p=10 \mathrm{bar}$ (bottom row) for the case $N_{0}=1.1 N_{0, \text { ext }}$ during the extinction transient. 